subtlety is needed, however, in dismissing the attempts by some other hospital staff to influence or control doctors' professional activities. Porters, for example, have no place in clinical medicine; nor can ambulancemen be allowed to usurp a doctor's judgment. It is time for doctors and administrators to say this loud and clear. And if general practitioners think that there are only hospital problems they may be disturbed to know that unions are now recruiting members from among the staff of privately owned practice premises.

Some of these unhappy problems have resulted from years of low pay, poor management, and understaffing of the NHS, with industrial action seen as the only way of achieving improvements. Doctors are no longer in such a strong position to criticise that. But having discovered the power they wield, the nursing, technicians, and other health workers' unions are using it to develop their influence on the management of the NHS, with administrators generally unwilling or even frightened to confront them when this influence is clearly detrimental to patient care. The patient is being used as a pawn, with militant unionists arguing that their actions are for his long-term benefit, a travesty of the ethic that the patient comes first. Thus decisions on closing hospitals, on improving departments' efficiency, or on allocating funds according to rational priorities are being stalled or even stopped by threat of militant action. While rational discussion in committee does not always achieve satisfactory results, surely it is preferable to the anarchy of arbitrary obstruction, when any decisions are taken along the line of least resistance.

This path will lead to demoralisation, chaos, and a breakdown of the Service. What is particularly depressing in this jungle of industrial relations in the NHS is the lack of any leadership from the DHSS. Health authority administrators may be criticised for their role in appeasement, but the silence of the DHSS in union-initiated disputes can give them no encouragement. The dangers of these internecine differences and battles for power and influence in the NHS are clear: the patient is at risk of being forgotten. So let us restate the obvious: the NHS exists to look after sick people. Its objective is not to guarantee employment for those who work in itwhether they stoke obsolescent boilers or do research into obscure diseases. Hospitals are there to serve the patient, who should not have to depend on a porter's whim for the time he arrives at the operating theatre.

What the patient needs is to be seen, diagnosed, treated, and cured by a competent doctor. All other activity and planning in the NHS are secondary to this end. Future generations will not forgive us for condoning appeasement in the 1970s, any more than we forgive those of our forebears who hailed the Munich agreement.

\footnotetext{
1 British Medical fournal, 1977, 2, 1610.

2 Dyson, R, The Management of Pathology Laboratories. London, Association of Clinical Pathologists, 1977.
}

\section{Hidden hazards of cremation}

In recent years the number and variety of metal and plastic objects implanted in patients have increased steadily. These include joint prostheses, nails and splints for fractured bones, heart valves, and cardiac pacemakers. At one time pacemakers were occasionally removed post mortem for later reimplantation, mainly for reasons of cost. Nevertheless, nowadays in Britain it seems to be the rule that when a patient with a prosthesis dies no attempt is made to recover it, even though metallic prostheses generally show no evidence of structural defect. $^{1}$ In some less wealthy countries prostheses are still recovered and reimplanted with considerable saving in cost, and the time may come when we may have to adopt the same practice here. Meantime, however, non-combustible objects are being found more and more often among the remains after cremation: indeed, one survey ${ }^{1}$ found that $5^{\prime \prime}{ }^{\circ}$ of bodies undergoing cremation contained metallic objects-and, though most were orthopaedic implants, a Spencer-Wells forceps and a bowel clamp were also found.

Little notice was taken of the presence of surgical hardware post mortem until September 1976, when the mercury zinc batteries in a pacemaker left in a body exploded during cremation $^{2}$ with force sufficient to damage the brickwork lining of the cremation chamber. The strength of the explosion had possibly been increased by the presence of hydrogen produced in near-exhausted batteries. In the course of their duties those working at the crematorium periodically observe the process of cremation, and an explosion on this scale could cause injuries or even death. A further risk is that such an explosion could release toxic gases or even infectious material from the corpse.

Lithium batteries may well replace zinc mercury batteries in pacemakers, and when heated to a high temperature these are even more explosive. Moreover, since 1970 pacemakers powered by plutonium-238 have been tested clinically in several centres and have proved their worth. Since these contain up to $3 \mathrm{Ci}$ of the isotope patients have been closely supervised and as a routine the pacemaker is removed after death. It takes about one hour at $800^{\circ} \mathrm{C}$ to cremate a body, and the latest models of plutonium pacemaker have now to pass a very stringent "cremation test" of withstanding $1300^{\circ} \mathrm{C}$ for $1 \frac{1}{2}$ hours. This should ensure that they could not leak during cremation, but it is also an admission that recovery post mortem may not be invariable. Possibly the same cremation test may eventually be demanded for all types of pacemakers. Even so, in the meantime, their federation has advised cremation authorities to ask area health authorities to add, as an interim measure, two questions to the statutory cremation form $\mathrm{B}$, which is completed by the doctor who attended the deceased in his last illness. The questions ask the doctor signing form $\mathrm{B}$ whether a pacemaker (or any radioactive material) was present in the body and whether it had been removed. Coroners are expected to take similar action with form $\mathrm{E}$. The federation has also advised medical referees to consider refusing to accept for cremation any body containing a pacemaker.

The 1972 code of practice ${ }^{3}$ lays down that there is no contraindication to cremating corpses containing up to $30 \mathrm{mCi}$ of yttrium-90, iodine-131, or gold-198 or $10 \mathrm{mCi}$ of phosphorus- 32 (on the assumption, presumably, that a radioactive isotope in the tissues would be expected normally to disperse harmlessly up the smoke stack). Nevertheless, the Federation of Cremation Authorities is also concerned about possible hazards from radioactive substances left in bodies brought for cremation. There is a possibility that an explosion (or some other event) during the cremation of a radioactive corpse could produce a blow-back releasing radioactive smoke or fumes into the crematorium. This risk seems to be largely theoretical, but a more serious cause for concern arises when the radioactive isotope is confined within a sealed container. Isotopes such as caesium-137 or iridium-192 are available for therapeutic use in amounts up to $75 \mathrm{mCi}$ in the form of needles, tubes, grains, and pins. Moreover, radium itself, which has a very long half life, is also still used in needle form. 
If such a source leaked during cremation the radioactivity would be dispersed harmlessly with the smoke, but nowadays therapeutic isotopes are normally contained in welded iridioplatinum or stainless steel capsules which should withstand the $800^{\circ} \mathrm{C}$ of the cremation furnaces. The implant would therefore survive as a radioactive object which would be hazardous to a cremator operator if he handled it directly.

A body intended for cremation which contains a pacemaker or a radioactive implant should not, therefore, be released to an undertaker. The pacemaker should be removed, but if it is not possible to remove a radioactive implant the undertaker should be given precise information regarding its nature, size, and location.

1 Thomas, H O, fournal of Bone and foint Surgery, 1976, 58B, 135.

2 Morrell, P J, Practitioner, 1977, 219, 109.

${ }^{3}$ Code of Practice for the Protection of Persons against Ionizing Radiations arising from Medical and Dental Use (Appendix 7 ). London, HMSO, 1972.

\section{Targets for prevention}

The most charitable view of Mr David Ennals's White Paper ${ }^{1}$ on prevention is that he really believes that people change their way of life when told to do so. For the last two years the DHSS has been singing the praises of a preventive approach to health, and the stream of exhortations, warnings, and advice seems never-ending: yet in terms of positive action the Government has done virtually nothing.

Last April the House of Commons Expenditure Committee (which had spent months taking evidence from medical experts) published a set of detailed proposals, ${ }^{2}$ which we welcomed ${ }^{3}$ as "concise and uncompromising." How has the DHSS, with its self-proclaimed commitment to prevention, responded?

On smoking the committee recommended a ban on tobacco advertising except at the point of sale; the abolition of cigarette coupons; the restriction of cigarette machines to premises to which children have no access; and a specific warning on cigarette packets that smoking causes cancer, bronchitis, and heart disease. Those proposals have all been flatly rejected. The Government is "considering" the recommendation that the price of cigarettes should be increased annually, but, says the White Paper, "tax increases raise the cost of smoking for those least able to afford it ... other factors ... include ... the implications for wage negotiations." In other words, the Government is not prepared to take action that might be unacceptable to any substantial part of the population.

This chicken-hearted approach has been followed with many of the other proposals from the Expenditure Committee. The MPs had drawn attention to the close association between alcohol consumption and the price of drink; but the Government is not at present prepared to maintain liquor prices relative to average incomes, let alone increase them. On fluoride the Government simply continues to "promote the general introduction of fluoridation." Even on the simple issue of encouraging exercise the White Paper claims that "not enough is known about all the implications for health of exercise," using the old excuse of that "further research is required to avoid doing anything constructive. Nevertheless, some of the decisions are to be welcomed-in particular, the recognition by the DHSS that there is no case for a nationwide screening for breast cancer and the increased support for the Health Education Council; but most of the paragraphs are platitudinous or simply promise yet more publications from the DHSS, whose paper productivity is symptomatic of the troubles of the NHS.

The glaring omission from the document is that there is no hint of constructive Government action to tackle the current epidemics of deaths and injuries from road accidents. The Transport Secretary, Mr Rodgers, is said ${ }^{4}$ to be waiting for public opinion to be convinced before contemplating legislation to make the use of car seat belts compulsory. Yet all the evidence from other parts of Europe and from Australia, where compulsion has proved its lasting benefits, shows that the force of law is the only way to persuade drivers to use belts. ${ }^{5}$ Britain is equally out of date in its permissive attitudes to pedestrians: in what other countries with comparable traffic congestion may people dash across the road when and where they like? Stricter enforcement of speed limits and tighter controls over drinking and driving (as recommended last year by the Blennerhasset Committee) are straightforward measures which could reduce the load on the NHS, but they have been ducked, fudged, or postponed indefinitely by a Government which lacks the courage to take any action that might be unpopular with any section of the electorate.

${ }^{1}$ Department of Health and Social Security, Department of Education and Science, Scottish Office, Welsh Office, Prevention and Health. London, HMSO, 1977.

${ }^{2}$ Preventive Medicine. First Report from the Expenditure Committee. London, HMSO, 1977.

${ }^{3}$ British Medical fournal, 1977, 1, 989.

4 The Times, 15 December, 1977.

${ }^{5}$ British Medical fournal, 1977, 1, 593.

\section{Country health}

Is town or country life preferable? The answer depends on the individual. But which is the more healthy? No dogmatic answer can be given-the disease pattern varies with the rural and urban areas compared. Is the familiar concept of the ruddyfaced, healthy countryman correct, or do rural communities, as a recent article from Australia suggested, ${ }^{1}$ contain a higher incidence of chronic illness than is generally realised? To answer that question we need to examine the age structure of rural communities and the occupational hazards of farming.

In most remote parts of Britain the population has not increased over the past 100 years, owing mainly to an exodus of healthy young adults seeking jobs elsewhere. Often a small influx of retirement pensioners upsets the age balance further. In consequence many country areas have a high proportion of elderly people, and so we should expect a relatively high prevalence of chronic illness. Other population movements also occur. Rural areas abound with static caravan sites, which seem to attract people with special problems-often monetary, sometimes marital-which add to the morbidity within the rural area.

Agricultural workers are highly skilled, and low income is but one of their many occupational hazards. The hours of work are long; their working environment may be inclement and dangerous; sudden deaths from falls and accidents with animals and machinery occur with unpleasant frequency, but these are rarely noted outside the local community. Less severe accidents are numerous-injuries to feet from rusty 